\title{
Моделирование распространения ультракороткого импульса большой мощности в двулучепреломляющем одномодовом оптическом волокне
}

\author{
В.А. Бурдин \\ Поволжский государственный университет телекоммуникаичий и информатики \\ E-mail: burdin@psati.ru
}

DOI: 10.31868/RFL2020.77-78

В настоящее время фемтосекундные лазеры находят все большее применение в различных отраслях. Разнообразие их приложений требует различные формы, длительности, мощности оптических импульсов. Нередко создание лазеров с необходимыми параметрами импульсов и средств доставки импульсов к месту приложения требует разработки специальных оптических волокон. Однако достаточно часто для этих целей могут быть использованы и типовые конструкции кварцевых волокон. Причем особенно востребованы оптические волокна с сохранением поляризации. Для описания процессов распространения оптических импульсов в двулучепреломляющих оптических волокнах с учетом нелинейности, дисперсии и связей мод хорошо зарекомендовала себя модель, базирующаяся на решении системы связанных нелинейных уравнений Шредингера, которую в ряде случаев приводят к уравнениям Манакова. Как правило данную систему решают методом расщепления по физическим процессам. Метод обладает рядом преимуществ, обеспечивая приемлемую погрешность при относительно низких требованиях к вычислительным ресурсам. При моделировании распространения в оптических волокнах ультракоротких оптических импульсов длительностью менее 10 пс необходимо учитывать также и хроматическую дисперсию третьего порядка, и эффект рассеяния Рамана. Для этого в уравнения системы вводят дополнительные члены. В результате, при решении данной системы уравнений методом расщепления по физическим процессам нелинейный оператор включает производные функций от комплексной огибающей по времени. Это и является основной проблемой реализации метода расщепления по физическим процессам для решения системы связанных нелинейных уравнений Шредингеровского типа с компонентами для учета эффекта Рамана.

В $[1,2]$ предложено нелинейный оператор привести к системе уравнений Маделунга и выполнять его, решая эту систему дифференциальных уравнений на каждом шаге. Показано, что такой подход дает устойчивые решения в отличие от прямого вычисления нелинейного оператора с производными комплексной огибающей по времени, вычисляемой непосредственно численными методами или с помощью преобразования Фурье. При этом, были рассмотрены следующие варианты вычисления производных с помощью преобразования Фурье:

$$
|A|^{2} F^{-1}[j \omega F(A)] \text { и } F^{-1}\left[j \omega F\left(|A|^{2}\right)\right]
$$

Здесь $F$ и $F^{-1}$ - оператор прямого и обратного преобразования Фурье, соответственно; $A$ - комплексная огибающая; $\omega$ - круговая частота; $\mathrm{j}$ - мнимая единица. В [3] предложено вычислять производную от интенсивности следующим образом 


$$
\operatorname{Re}\left\{F^{-1}\left[j \omega F\left(|A|^{2}\right)\right]\right\}
$$

Этот вариант использовался и в данной работе, но в отличие от [3] здесь пренебрегали нелинейной составляющей коэффициента перед первой производной комплексной огибающей по времени. Предварительно, применяемый алгоритм реализации метода расщепления по физическим процессам для решения рассматриваемой системы связанных нелинейных уравнений Шредингера, описывающей процесс распространения оптического импульса большой мощности в одномодовом оптическом волокне с двулучепреломлением тестировался на примере, для которого известны экспериментальные данные.

В частности, моделировали распространение оптического импульса длительностью 12 фс с пиковой мощностью 175 кВт в двулучепреломляющем одномодовом волокне типа «бабочка» на длине волны 798 нм. Результаты вычислений отклика на выходе оптического волокна достаточно хорошо совпали с экспериментальными данными как во временной, так и в спектральной областях. При этом, предложенный алгоритм в отличие от [1] исключал необходимость решения дополнительной системы дифференциальных уравнений на каждом шаге решения, а количество преобразований Фурье, необходимых для прямого вычисления нелинейного оператора метода расщепления по физическим процессам сократилось в два раза. В дальнейшем было выполнено моделирование для образцов оптического волокна большей протяженности в зависимости от длины биений волокна с сохранением поляризации и распределения оптической мощности между модами на входе. Пример полученных результатов моделирования распространения оптического импульса длительностью 12 фс в оптическом волокне приведен на рисунке 1. Представленные в работе результаты моделирования наглядно демонстрируют существенную зависимость искажений импульса в двулучепреломляющем волокне от длины биений и условий ввода.

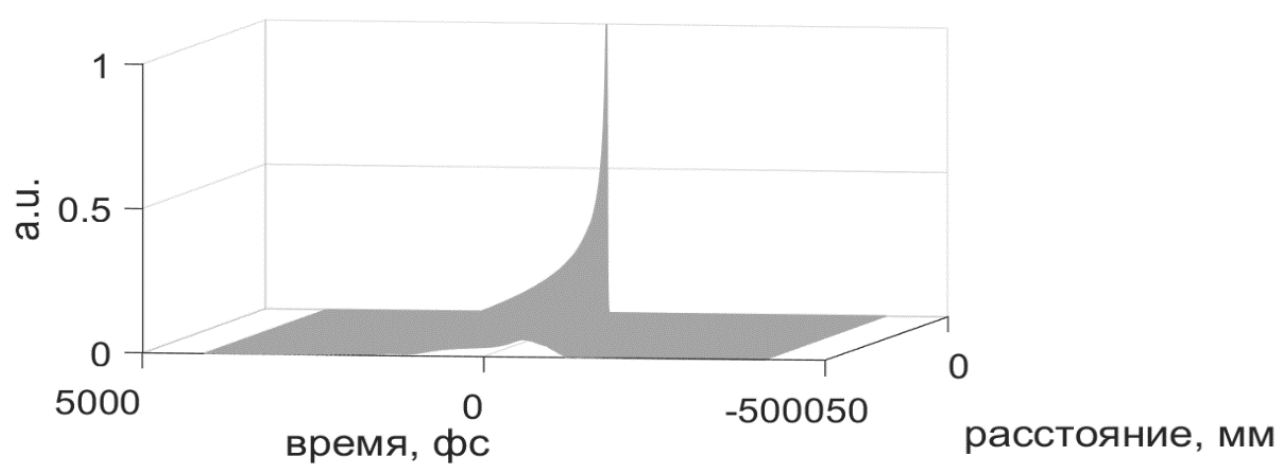

Рис. 1 Эволюция фемтосекундного импульса большой мощности при распространении по двулучепреломляющему одномодовому оптическому волокну.

\section{Литература}

[1] R. Deiterding, R. Glowinski et al, J. Lightwave Technology 31(12), 2008-2017 (2013)

[2] B. R. Deiterding, S.W. Poole, arXiv:1504.01331 [math.NA] (2015)

[3] R. Deiterding, S.W. Poole, Splitting Methods in Communication, Imaging, Science, and Engineering. Scientific Computation. Springer, Cham (2016)

[4] В.А. Бурдин, А.В. Бурдин, Прикладная фотоника 6(1-2), 93-108 (2019) 